\title{
Research Hotspots and Trends on TPACK in WOS Based on Visual Analysis
}

\author{
Chuan Xue, Wei He* \\ School of Education Science, Nanjing Normal University, Nanjing, China \\ Email: ^1324122949@qq.com
}

How to cite this paper: Xue, C., \& He, W. (2021). Research Hotspots and Trends on TPACK in WOS Based on Visual Analysis. Open Journal of Social Sciences, 9, 305-321. https://doi.org/10.4236/jss.2021.92021

Received: January 11, 2021

Accepted: February 20, 2021

Published: February 23, 2021

Copyright $\odot 2021$ by author(s) and Scientific Research Publishing Inc. This work is licensed under the Creative Commons Attribution International License (CC BY 4.0).

http://creativecommons.org/licenses/by/4.0/

\begin{abstract}
This study adopted the bibliometric method to visually analyze 844 articles of TPACK from 2009 to 2020 in core collection database of Web of Science (WOS). The Visual analysis is conducted on the authors, research organizations, articles and keywords using CiteSpace to explore research hotspots and trends in research of TPACK in WOS. This paper reveals the most influential authors and institutions, highly cited articles, research hotspots and trends of TPACK research. The findings show that the research on TPACK has been moving forward and making significant development. The core author Ching Sing Chai of Nanyang Technological University is a typical representative, having published lots of influential articles. Nanyang Technological University is also the most influential institution. We can see that not only TPACK and PCK are the hotspots of research, but also "digital competence", "educational technology" and "learning by design" are hot research topics. "Learning activity", "professional knowledge", "pedagogical model", "teaching materials" are all the research trends of TPACK. Researchers are likely to integrate TPACK with more disciplines to enhance the applicability of TPACK and enlarge the research scope of TPACK in the future.
\end{abstract}

Keywords

TPACK, TPCK, Hotspots, Trends, CiteSpace

\section{Introduction}

The technological pedagogical content knowledge (originally TPCK, now known as TPACK) framework is derived from the conception of pedagogical content knowledge (PCK), which was proposed by Shulman (1986). Koehler and Mishra 
(2005) demonstrated that teaching is a complicated practice, so effective teaching requires integrated and well-organized knowledge, including knowledge of pedagogical, knowledge of content, and knowledge of technology, and added technological " $\mathrm{T}$ " to pedagogical content knowledge. The interaction of these knowledge systems has produced flexible knowledge, which can successfully integrate knowledge into teaching in theory and practice. After several years of development, the most complete descriptions of the conception of TPACK are found in Koehler and Mishra (2009). The TPACK is a framework for understanding and describing the kinds of knowledge teachers that need to engage in effective instructional practices in technology-enhanced learning environments. Content, pedagogy, and technology are three main components of TPACK framework. The intersections of these knowledge systems are equally important and are denoted as PCK, TCK (technological content knowledge), TPK (technological pedagogical knowledge) and TPACK. In order to provide meaningful and valuable reference for future studies in the field of TPACK, this research explores research hotspots and trends of TPACK. With Citespace 7.5, through the analysis of the core authors, research institutions, top cited articles and high frequency keywords about the TPACK, research hotpots, research trends and research context of TPACK are being visually shown.

\section{Literature Review}

The TPACK framework provides us with a brand-new consideration of the professionalism of teachers. It focuses on teachers' knowledge development, especially related knowledge that can integrate technology into the learning environment to achieve effective teaching. Since it was proposed, many scholars have attempted to study TPACK theoretically and in practice, and some scholars also have reviewed the development of TPACK research. For example, Voogt et al. (2013) investigated the theoretical basis and the practical application of TPACK conducted from 2005 to 2011; Chai, Koh and Tsai (2016) discussed the gaps in the research at that time and explored the possible future directions for the development about the quantitative measures of TPACK; Gür and Karamete (2015) reviewed the ICT and TPACK literature for teacher education; Wang, Schmidt-Crawford and Jin (2018) provided a comprehensive report, which examined the documented results of TPACK development for pre-service teachers. Up to now, there has been some systematic research about the development of TPACK.

Bibliometrics is widely used in academic research to determine the development patterns of a research field effectively and is a valuable literature analysis tool. Despite there has been some systematic research about the development of TPACK, there have been few researchers to use bibliometrics gathering systematic data to analyze the research hotspots and trends of TPACK. This study adopted the bibliometric to visually analyze the research achievements of TPACK from 2009 to 2020 in core collection database of WOS. 


\section{Data and Visual Tool}

\subsection{Data Collection}

This paper used "TPACK" or "TPCK" as the search topic to retrieve related articles in core collection database of WOS, which was the only comprehensive one to provide citation data, had a dominant position in the field of academic reference, mainly through the annual journal impact factor (Bar-Ilan, 2007; Falagas, Pitsouni, Malietzis, \& Pappas, 2008). Additionally, the general search strategy in WOS core collection database was adopted. As is known, Koehler and Mishra added technological "T" to PCK, getting TPCK or TPACK when the time came to 2005 (Archambault \& Crippen, 2009). There are fewer articles about TPACK between 2005 and 2008, so the publication time limitation is 2009-2020. After the search process, up until November 10th, 2020, there are 1144 articles that include the TPACK or TPCK (Figure 1) in the WOS. Excluding irrelevant papers, such as TPACK in the communication field, TPCK in the biology field, etc., 844 journals are finally chosen.

\subsection{Visual Tool}

The chosen papers were saved to Other File Formats in plain text, including the full record and cited references to be analyzed in CiteSpace. CiteSpace is a Java application, which can be used for data mining, visualization of information, bibliometrics, and integrate these three functions into an interactive visualization tool easy for extracting patterns in citation data (Synnestvedt, Chen, \& Holmes, 2005). The primary goal of CiteSpace is to visually analyze the literature in a specific field to explore the research hotspots and trends. Each paper from each journal has been indexed so that there is the most comprehensive citation network to support confident discovery and trustworthy evaluation in WOS.

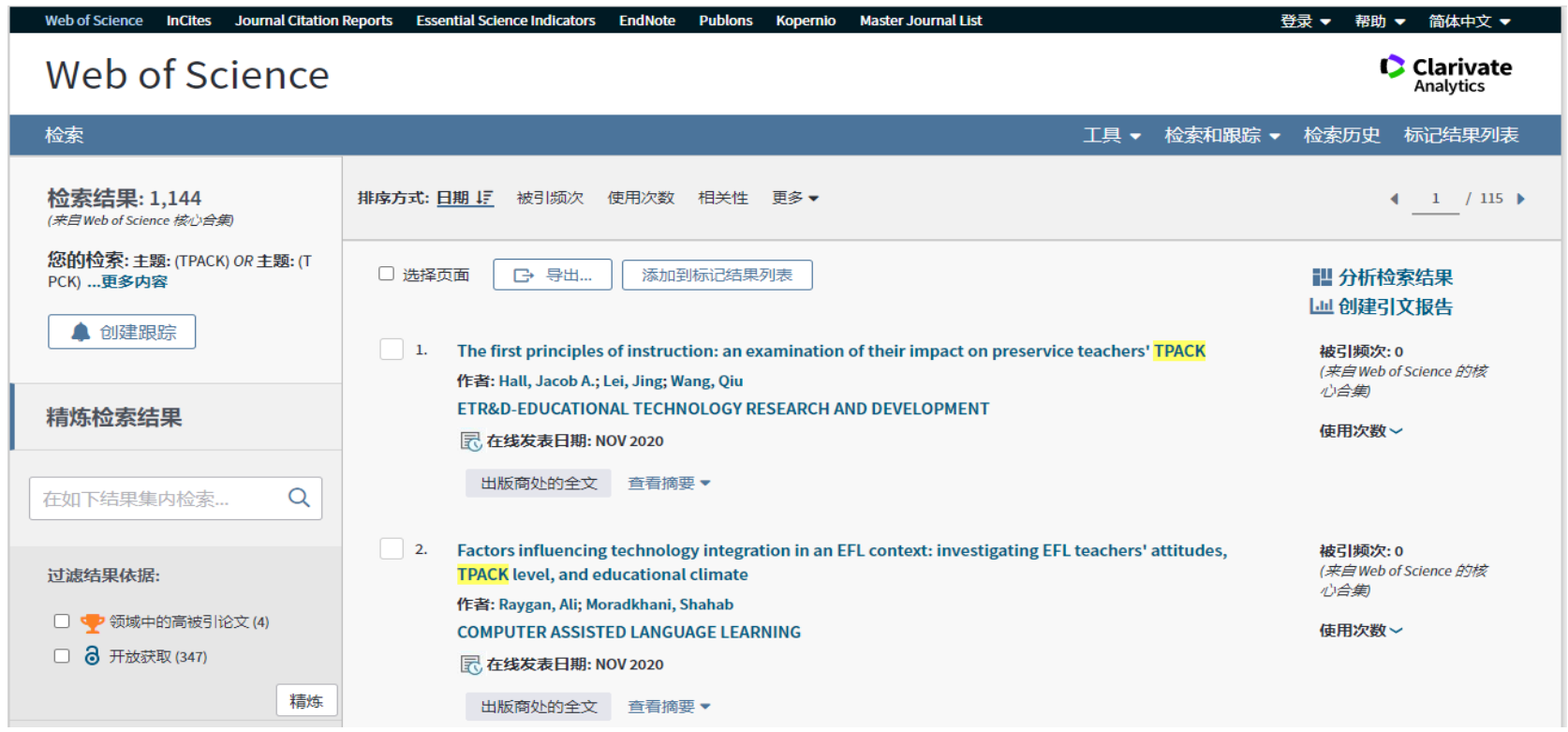

Figure 1. Results of general search in WOS (2009-2020). 
That makes it easier for us to make a co-citation analysis of all the papers in Citespace. From the literature co-citation network, we can see the research hotspots' theoretical basis, and from the keyword co-occurrence network, we can find the research hotspots. In the study, CiteSpace 5.7 was applied to analyze 844 articles related to TPACK in core collection database of WOS from 2009 to 2020. It was used to map the knowledge from four aspects, author, research institution, cited articles and keywords, respectively.

\section{Visual Analysis}

\subsection{Number of TPACK Papers}

As for the number of published academic papers, it can reflect the trends of a specific research. According to the "Create Citation Reports" function that comes with the WOS, we can see the annual volume of the TPACK research.

According to the quantitative analysis results, the number of published papers each year overall rapidly increased during this period from the given trend dotted line. As is shown in Figure 2, since 2009, research on TPACK has gradually appeared in the core collection database of WOS. By 2015, the literature on TPACK research has shown an overall rapid upward trend. Until 2019, the number of published papers was the most with 156 articles. Two important reasons are TPACK theoretical framework tends to be completed and there have been many researchers on education applying TPACK.

\subsection{Core Authors and Research Institutions}

Research on authors with high academic productivity will enable us to grasp the development trend of this research field and obtain a broader perspective. The analysis of research institutions will indicate which institutions are at the frontier of the research. "Author" and "Institution" were selected in the node type in Citespace, authors and research institutions in the top ten are shown in Table 1,

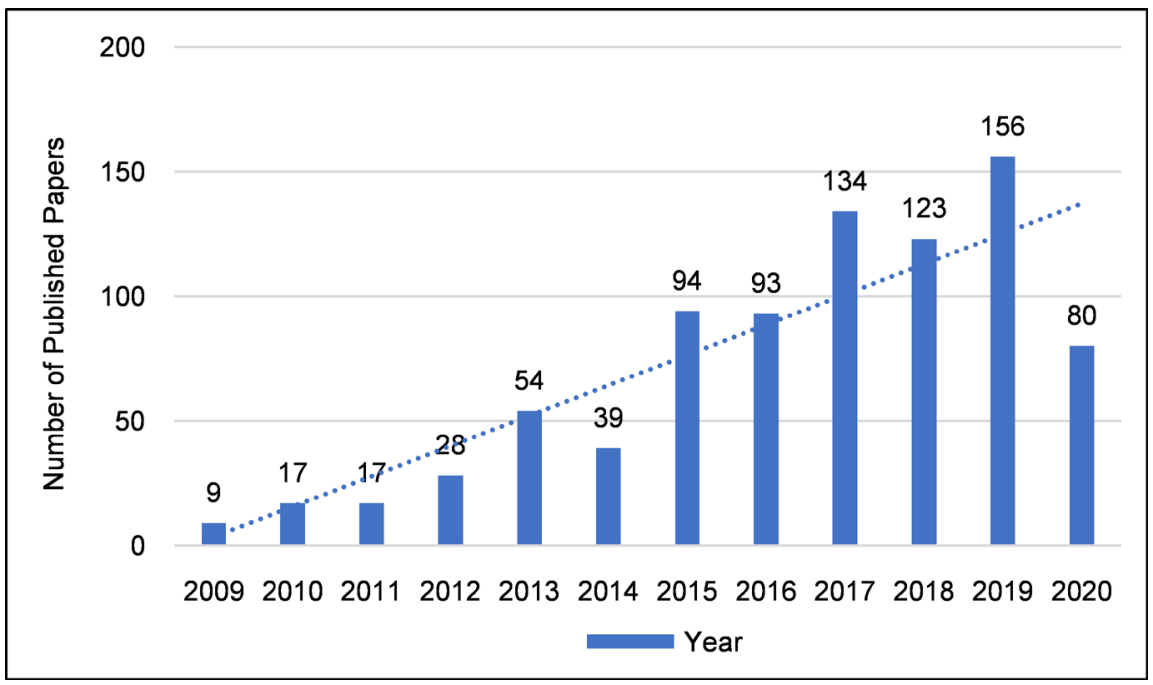

Figure 2. The number of published papers in WOS (2009-2020). 
Table 1. The co-occurrence graph of authors/research institutions of TPACK in WOS (2009-2020).

\begin{tabular}{cccccc}
\hline No. & Frequency & Core Authors & No. & Frequency & Research Institutions \\
\hline 1 & 35 & Ching Sing Chai & 1 & 38 & Nanyang Technological University \\
2 & 23 & $\begin{array}{c}\text { Joyce Hwee } \\
\text { Ling Koh }\end{array}$ & 2 & 18 & $\begin{array}{c}\text { National Taiwan University of } \\
\text { Science and Technology }\end{array}$ \\
3 & 14 & Chinchung Tsai & 3 & 17 & Universitas Pendidikan Indonesia \\
4 & 13 & Hai Zhang & 4 & 15 & National Taiwan Normal University \\
5 & 11 & Tondeur Jo & 5 & 13 & Northeast Normal University \\
6 & 9 & Yining Wang & 6 & 13 & University of Twente \\
7 & 7 & Voogt Joke & 7 & 11 & University of Amsterdam \\
8 & 7 & Jyh-chong Liang & 8 & 10 & The Chinese University of Hong Kong \\
9 & 5 & Evrim Baran & 9 & 8 & Anadolu University \\
10 & 4 & Bart Rienties & 10 & 8 & Middle East Technical University \\
\hline
\end{tabular}

respectively. In terms of the number of publications, Ching Sing Chai, Joyce Hwee Ling Koh and Chinchung Tsai are the top three authors. As for productive institutions, Nanyang Technological University, National Taiwan University of Science and Technology and Universitas Pendidikan Indonesia are the top three institutions.

The author co-occurrence graph (Figure 3), which is also named the author collaboration graph, can identify the core academic group of TPACK research. In the author co-occurrence graph, the names of the authors show at each node. The size of the author's name and the node size represent how many papers the author has published. The label size represents centrality. The lines depict the collaboration between authors. The author co-occurrence graph is with a total of 192 links and 339 nodes. According to the Price law (Price, 1963), we can calculate the number of the core authors of studies on TPACK. It can calculate with the equation $\mathrm{m}=0.749\left(\mathrm{n}_{\max }\right) 0.5$, where $\mathrm{n}_{\max }$ indicates the number of articles published by the highest producing author. In this study, $\mathrm{n}_{\max }$ is 35 , so $\mathrm{m}=4.43$, rounded to 4 . This means that the core authors of TPACK research have published at least four articles. Finally, the number of core authors is 16.

The institution co-occurrence graph (Figure 4), which is also named the institution collaboration graph, can be used to find out the core institutions of TPACK research. In the institution co-occurrence graph, the names of the institutions show at each node. The institution co-occurrence graph is with a total of 180 links and 277 nodes. The density of the network is 0.0047 . Q value is 0.33 , and $\mathrm{S}$ value is 0.97 . It shows that the research institution community formed by TPACK is significant. In Figure 4, we can see that Nanyang Technological University, National Taiwan University of Science and Technology, Northeast Normal University and University of Twente are the core research institutions. 


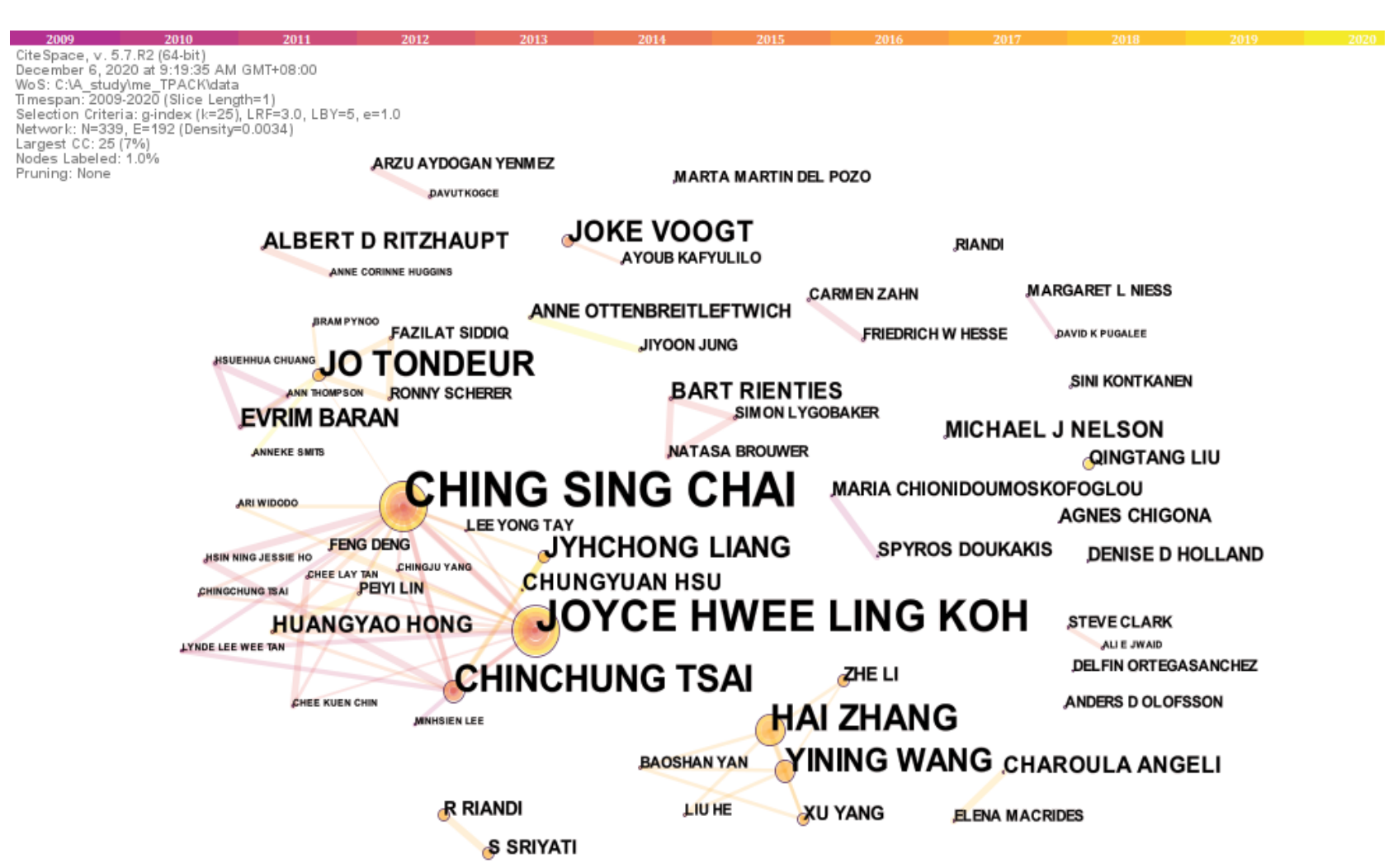

Figure 3. The co-occurrence graph of TPACK authors in WOS (2009-2020).

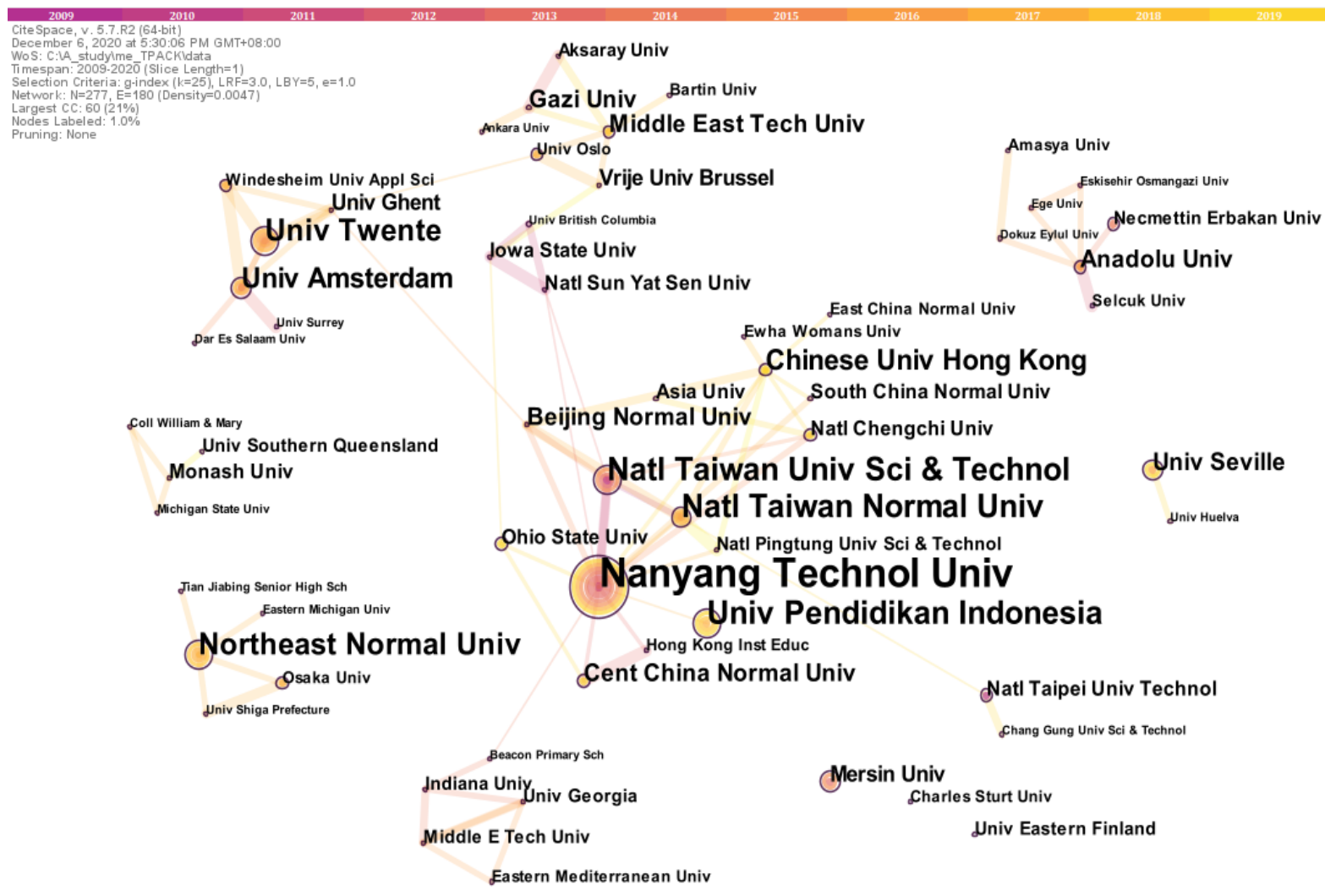

Figure 4. The co-occurrence research institutions of TPACK in WOS (2009-2020). 
However, the centrality of each core institution is also not high and the highest centrality of Ching Sing Chai is just 0.04 , so it can assume that there is a lack of cooperation between research institutions.

\subsection{Top Cited Articles}

The concept of co-citation was first introduced by Small (1973), an American intelligence scientist, which can be used to measure the degree of relationship between literature. The study of literature co-citation networks can explore the development and evolutionary dynamics of a research field. The core function of CiteSpace is to generate a unique co-citation network consisting of a combination of multiple literature co-citation networks.

Table 2 presented those high citation publications that are essential knowledge in TPACK field. The paper of Voogt et al. (2013) is a review of the literature about TPACK, which has the highest citations with 95, and was published in Journal of Computer Assisted Learning. Among those top 10 cited articles, 5 of them were published in Computers and Education. Besides, by content analysis of those literature, it revealed that there are 3 articles about TPACK theoretical framework, 2 articles for review of the TPACK, and 5 articles about research on the application of TPACK theoretical framework in practice. Four of these articles are about teacher development, namely, TPACK for assessing pre-service teachers' competencies; Exploring teachers' self-efficacy and TPACK; Modeling TPACK of elementary school pre-service teachers to promote meaningful learning; Exploring TPACK for elementary school math and science teachers in Taiwan. From this, we can come to this point of view that TPACK theoretical framework is widely used for the development of teachers, especially pre-service teachers.

Table 2. Top cited articles in the field of TPACK in WOS (2009-2020).

\begin{tabular}{ccccc}
\hline No. & Authors & Institution & Journal \\
\hline 1 & Voogt Joke (2013) & University of Twente & Journal of Computer Assisted Learning \\
2 & Ching Sing Chai (2013) & Nanyang Technological University & Educational Technology \& Society \\
3 & Charles R. Graham (2011) & Brigham Young University & Computers \& Education \\
4 & Denise Schmidt-Crawford (2009) & Iowa State University & Journal of Research on Technology \\
5 & Min-Hsien Lee (2010) & National Taiwan Normal University & Instructional Science \\
6 & Charoula Angeli (2009) & University of Cyprus & Computers \& Education \\
7 & Leanna Archambault (2010) & Arizona State University & Computers \& Education \\
8 & Ching Sing Chai (2011) & Nanyang Technological University & Computers \& Education \\
9 & Matthew J.Koehler (2014) & Michigan State University & Handbook of Research on Educational & 46 \\
10 & Joyce Hwee Ling Koh (2014) & Nanyang Technological University & Journal of Computer Assisted Learning & 49 \\
\hline
\end{tabular}




\subsection{Keywords Analysis}

\subsubsection{Keywords Co-Occurrence Analysis}

Knowing the hotspot is one of the keys to hold the trend frontiers of a specific field. By analyzing the keywords in the literature, we can capture the hotspots and core issues in the research field of TPACK. Through the keyword measurement visualization of CiteSpace, keywords with high frequency are analyzed to study the current research hotspots of TPACK. The top 15 keywords of TPACK research with the highest frequency from 2009 to 2020 are shown in Table 3. The top three keywords in the field of TPACK are "TPACK" with 469 times, "pedagogical content knowledge" with 318 times, and "framework" with 149 times, respectively.

In the field of TPACK research, "TPACK" is undoubtedly the highest frequent keyword. The core author Ching Sing Chai who has published 38 articles about TPACK, of which one highly cited article is "Facilitating pre-service teachers' development of technological, pedagogical, and content knowledge (TPACK)". In this article, the author emphasized the importance of integrated TPACK for pre-service teachers. He believed that technological knowledge, pedagogical knowledge and content knowledge are all vital knowledge necessary for pre-service teachers. It also discussed the design issues of ICT education curriculum for pre-service teachers. His another highly cited article (Chai, Koh, Tsai, \& Tan, 2011) is about empirical study of TPACK, trying to verify the rationality and effectiveness of the TPACK framework. In addition to teacher training, TPACK theoretical framework is widely applied in teaching optimization.

Table 3. The co-occurrence of TPACK keywords in WOS (2009-2020).

\begin{tabular}{|c|c|c|c|c|}
\hline No. & Frequency & Centrality & Year & Keywords \\
\hline 1 & 469 & 0.00 & 2010 & Tpack \\
\hline 2 & 318 & 0.00 & 2010 & Pedagogical content knowledge \\
\hline 3 & 149 & 0.05 & 2010 & Framework \\
\hline 4 & 120 & 0.01 & 2010 & Technology \\
\hline 5 & 112 & 0.02 & 2009 & Education \\
\hline 6 & 88 & 0.14 & 2009 & ITC \\
\hline 7 & 82 & 0.08 & 2010 & Technology integration \\
\hline 8 & 82 & 0.03 & 2009 & Teacher \\
\hline 9 & 16 & 0.00 & 2009 & Belief \\
\hline 10 & 70 & 0.13 & 2010 & Technological pedagogical content knowledge \\
\hline 11 & 70 & 0.02 & 2009 & Teacher education \\
\hline 12 & 68 & 0.32 & 2009 & Science \\
\hline 13 & 66 & 0.11 & 2009 & Integration \\
\hline 14 & 65 & 0.04 & 2009 & Model \\
\hline 15 & 63 & 0.03 & 2010 & Mathematics \\
\hline
\end{tabular}


Doering, Veletsianos, Scharber and Miller (2009) used the TPACK framework to design online learning environments for faculty professional development. Koh, Chai, Benjamin and Hong (2015) proposed a conceptual framework that articulated how to use TPACK as epistemic resources to support the design thinking for developing ICT-integrated curriculums. TPACK is also widely used to integrate with other disciplines, especially mathematics and physics.

The keyword "PCK" (Pedagogical Content Knowledge) is the focus of TPACK research. Since 2000, PCK research has involved education, computer science, psychology, sports science, linguistics, engineering, nursing, social science, environmental science and ecology, and public environment and health. The theoretical model research of PCK mainly focuses on education research. In contrast, the empirical research based on the construction of the theoretical model is applied to other different disciplines, such as nursing and social sciences.

\subsubsection{Keywords Clustering Analysis}

Keyword clustering analysis is one primary function of Citespace. It reflects the structural features among clusters, emphasizing important nodes and critical connections. To better understand the research hotspots and the highlight research topic, further cluster analysis of the co-occurrence of the keywords of TPACK was carried out.

Figure 5 shows the clustering keywords results. The value of modularity Q was 0.81 , which was higher than 0.3 , indicating that the clustering structure was significant. The value of $\mathrm{S}$ was 0.93 , which was higher than 0.7 , indicating clustering is convincing. The top 10 clusters are shown in the figure. Those 10 clusters were sorted according to the number of keywords contained, where a smaller sequence number indicates a larger category. CiteSpace uses algorithms to cluster closely related keywords, and then gives each keyword a value. In a cluster, the keyword with the largest value becomes the representative of the cluster.

As shown Figure 5, "digital competence", "educational technology" and "learning by design" are the largest three clusters. The first cluster is cluster0 "digital competence", containing 48 nodes. As the education professions face rapidly changing demands, the capabilities required by educators are more comprehensive and more complex than before. The popularization of digital devices and the responsibility of helping students improve their digital capabilities need educators to develop their digital capabilities. One of the main tasks in pre-service training of teachers is to enhance their digital competencies. It is necessary to find a framework that can assess the digital capabilities of educators. Cabero and Barroso (2016) proposed that the TPACK framework was useful as a theoretical conceptualization, which can substantiate an adoption of the digital competence of trainee teachers, whether it's at the beginning or during permanent lifelong training, and TPACK model also was a useful assessment tool. Redecker and Punie (2017) proposed that the TPACK model can be complemented with the digital competence of the educator framework. No wonder "digital competence" has become the number one hotspot in the field of TPACK research. 


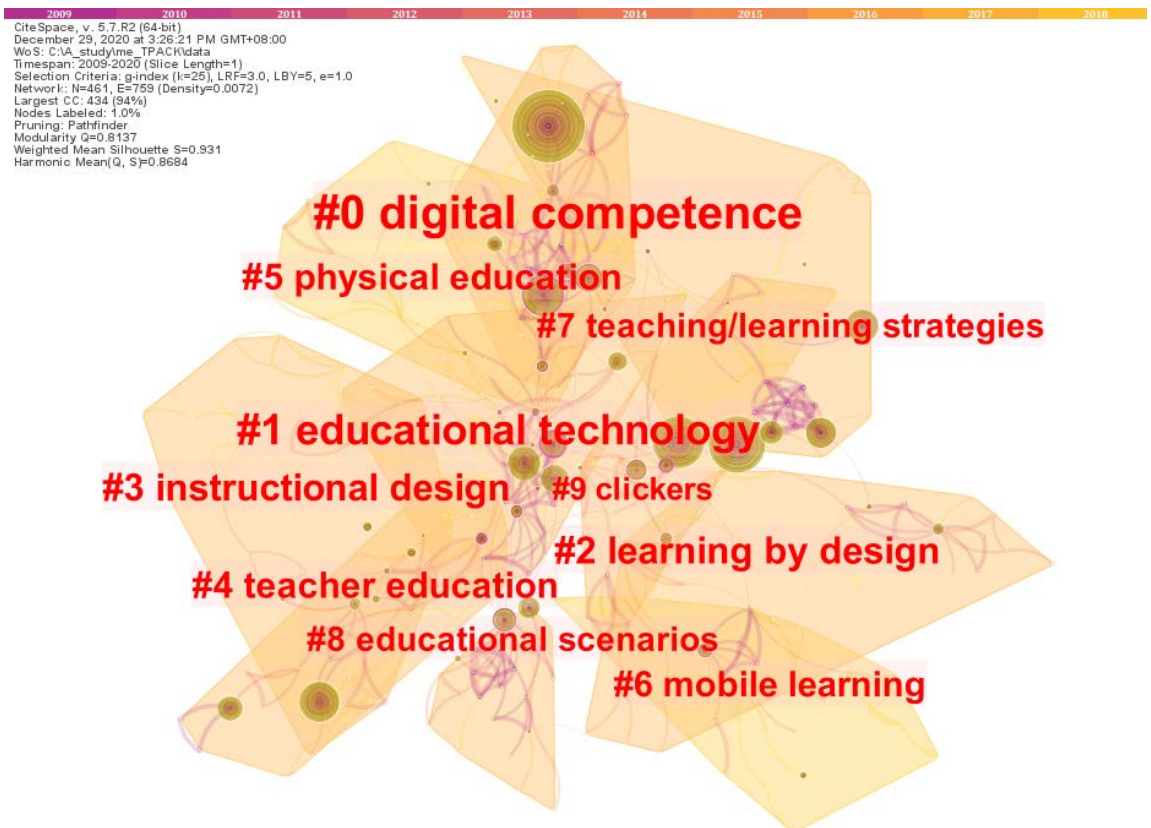

Figure 5. The Keywords clustering graph of TPACK research field in WOS (2009-2020).

The second cluster is cluster1, "educational technology", containing 40 nodes. There is no doubt that educational technology is the focus of TPACK research. In TPACK research, integrating technology, especially educational technology, into pedagogical content knowledge is the main content all along. Technology pedagogical content knowledge can help teachers with technology integration. A useful instructional model, learning by design, can support teachers in building technology pedagogical content knowledge. It can create a learning environment conducive to addressing the complex interplay between technology, pedagogy, and content, and help teachers develop TPACK (Lu, Johnson, Tolley, Gilliard-Cook, \& Lei, 2011). Thus, we can understand that "learning by design" is the third cluster.

\subsubsection{Keywords Timeline Analysis}

The keywords timeline graph shows the development of keywords contained in each cluster. Essentially, it also is a clustering graph, which just displays the keywords according to time. The keywords timeline of TPACK shows in Figure 6.

From the timeline graph, it can infer the development of TPACK. Between 2009 and 2020, TPACK is the most crucial research hotspot in the field of TPACK. Around 2010, several important research contents related to TPACK appeared, including instruction design, mobile learning, educational scenarios, etc. In 2011, learning by design became an important content of the TPACK research field, and until now, it had become a hotpot in TPACK research. In the following years, disciplines such as physics education and mathematics education were combined with TPACK. Many scholars use the TPACK theoretical framework to study pre-service education for teachers in a specific discipline or study how to integrate technology into a particular subject teaching. The researches of TPACK 


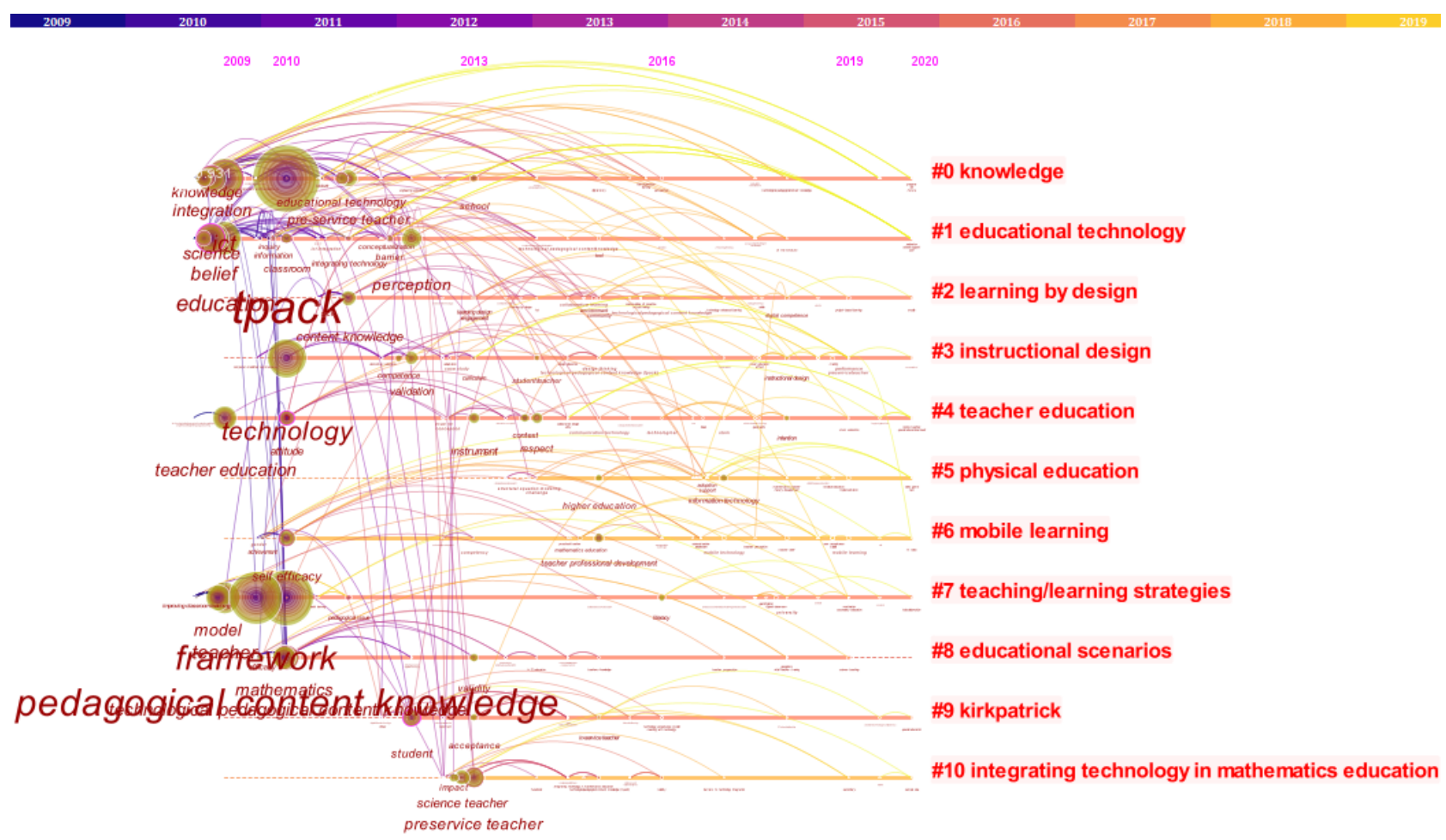

Figure 6. Timeline graph of TPACK research in WOS (2009-2020).

has been developing continuously and steadily. In the coming period, TPACK research will further improve its theoretical foundation and integrate with more educational technology, more disciplines to expand its research scope.

\subsubsection{Keywords Bursts Term Analysis}

The analysis of the research frontier trends provides a distinct perspective to reveal the context of TPACK research. CiteSpace uses burst detection algorithm to judge emerging research trends. Bursts refer to the words which are cited frequently in a short time. Figure 7 shows the keywords of TPACK with the strongest citation bursts. We can see that "higher education", "learning process", "learning activity" are mainly reflected from 2018 to 2020, and "professional knowledge", "pedagogical model", "teaching materials" are mainly reflected from 2019 to 2020, which are all the research trends of TPACK. To some extent, we can conclude that the research frontier trends of TPACK focused on the field of pedagogical model and learning process, mainly for higher education. Also, we can roughly infer that researches on pedagogical model and learning process for higher education are likely to be significant research content in the next period.

In order to find research hotspots and trends in research of TPACK, this article makes visual analysis of TPACK research from five aspects, the number of articles, author, research institution, cited articles and keywords, respectively. The number of published papers each year overall rapidly increased between 2009 to 2020, and the number of articles published in 2019 is the most. For authors with higher contributions, it can see that the core author Ching Sing Chai 
Top 18 Keywords with the Strongest Citation Bursts

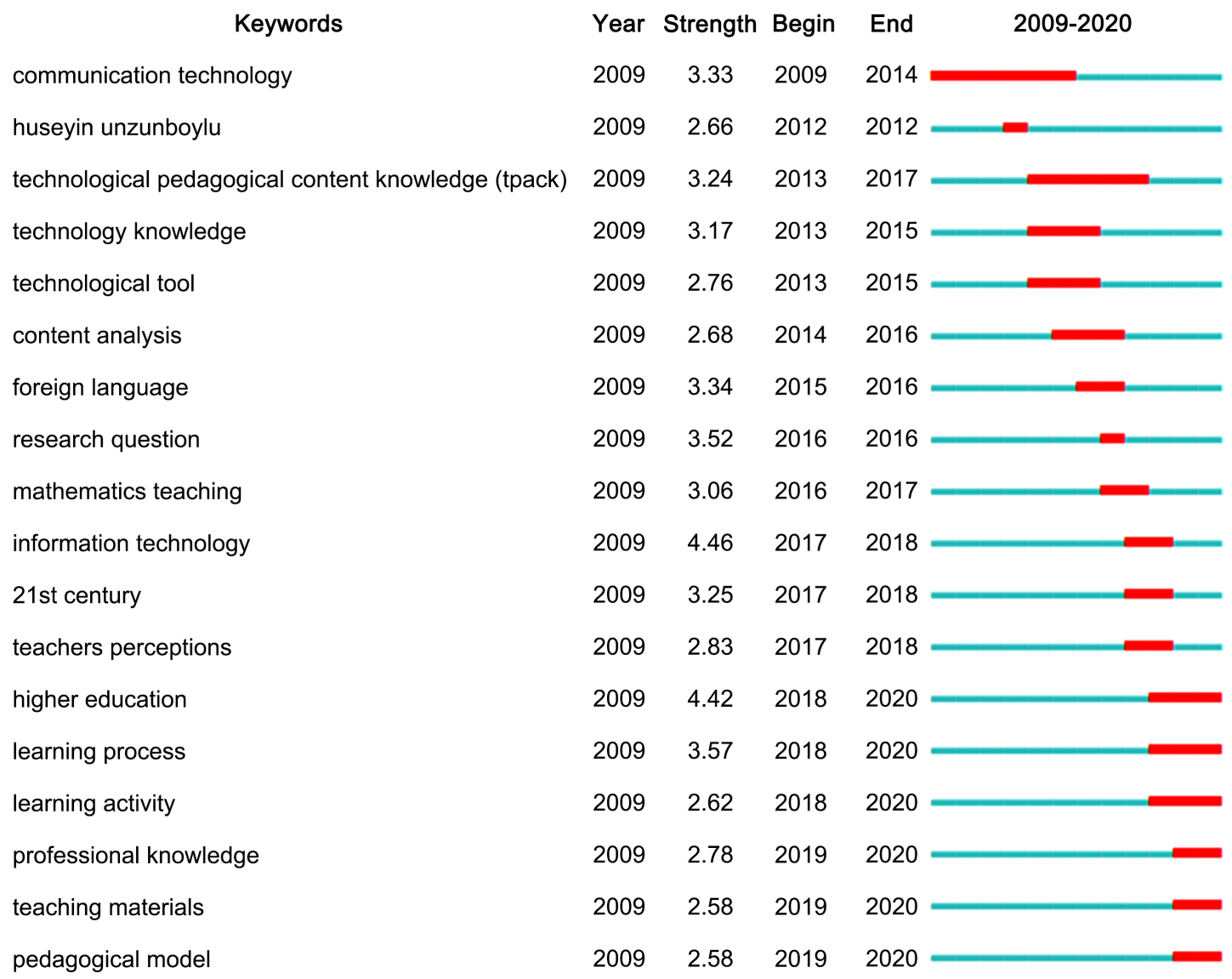

Figure 7. The bursts of TPACK in WOS (2009-2020).

is a typical representative, having published lots of influential articles, cooperated with Joyce Hwee Ling Koh and Chinchung Tsai. Ching Sing Chai and Joyce Hwee Ling Koh both worked at Nanyang Technological University which is also the most influential institution. As for cited articles, the paper of Voogt et al. (2013) has the highest citations with 95, which is a review of the literature about TPACK. The other top cited articles mainly are about the research of TPACK theoretical framework and its application in practice.

The focus of this article is keywords analysis, including co-occurrence analysis, clustering analysis, timeline analysis and bursts term analysis. From the keywords co-occurrence analysis, we can find that the most frequent words are "TPACK", "pedagogical content knowledge" and "framework". From the keywords clustering analysis, we can find that "digital competence", "educational technology" and "learning by design" are the largest three clusters. Keywords timeline analysis displays the keywords according to time, it can conclude that TPACK is the most crucial research hotspot in the field of TPACK between 2009 and 2020. From keywords bursts term analysis, it can judge research trends that "learning activity", "professional knowledge", "pedagogical model", "teaching materials" are all the research trends of TPACK. 


\section{Discussion}

\subsection{Status and Trend of TPACK Research}

TPACK research shows a steady rising trend in WOS in the past 12 years. In 2019, the number of published papers was the most, reaching the peak with 156 papers. TPACK theoretical framework tends to be completed and relatively mature. Teachers use TPACK as a conceptual tool that is widely used in teaching and learning for enhancing teaching effectiveness (Voogt, Fisser, Pareja Roblin, Tondeur \& van Braak, 2013). Those reasons explain why the development of TPACK research continues to grow, at the same time, indicating that TPACK research development may still keep increasing in the future. The topics with more concerned and heat are "TPACK", "PCK", "teacher education", "education technology", "learning by design", etc. The research scope of TPACK is extensive. TPACK can be seen as epistemic resources to support design thinking for developing ICT-integrated curriculums, can be used to integrate with elementary disciplines to optimize teaching, and can be seen as an evaluation tool for pre-service teachers. Thus, it can be considered that the development of TPACK research will be further expanded and explored in the future.

\subsection{Relationship between Research Subjects}

According to the Price law (Price, 1963), there are 16 core authors in the TPACK research field. As for the core research team, Ching Sing Chai of Nanyang Technological University, Joyce Hwee Ling Koh of Nanyang Technological University and Chinchung Tsai of National Taiwan University of Science \& Technology are typical representatives. They are also the top three authors as to the number of published articles, and they have cooperated closely and have published many articles with meaningful impact. They mainly applied technology, pedagogy and content knowledge to promote the development of pre-service teachers, becoming pioneers in this field. From the perspective of research institution, there are many TPACK research institutions distributed in many countries. In comparison, teacher education universities and technological universities focus on TPACK more than other types of universities, such as National Taiwan Normal University and Northeast Normal University, Nanyang Technological University, National Taiwan University of Science and Technology. Derived from the analyzed data, the centrality of each core author and institution is not high, that the centrality of Ching Sing Chai is only 0.01, the centrality of Nanyang Technological University is only 0.02 . Although there have been some outstanding achievements in TPACK research, it is clear that there is a lack of long-lasting collaboration between institutions and between researchers, let alone TPACK researchers collaborating with those in other research fields. In the next research, if TPACK researchers would like to have more breakthroughs in the TPACK research field and want to expand the scope of TPACK research further, active collaboration is an excellent way to choose (Franco \& Pinho, 2019). 


\subsection{Evolution and Trends of Research Topics}

Combining the analysis of top cited articles and the analysis of high-frequency keywords, the results show that the most attention has been paid to technological pedagogical content knowledge in recent years. With the development of education and technology, many scholars added new connotations to TPACK to perfect the theoretical framework of TPACK. For example, Olofson, Swallow and Neumann (2016) proposed "TPACKing", the product of the combination of constructivist theory and the TPACK theoretical framework, which can dynamically analyze teachers' knowledge construction. TPACK as a conceptual tool in research integrates with more disciplines to continuously expand the research field of TPACK. Another core research content, PCK, is not only the basis for the development of TPACK, but also an essential part of TPACK. In many interpretations of TPACK, PCK will be traced back. It is recommended that TPACK is a particular case of PCK, and believed that when teachers use unfamiliar technology products to accomplish instructional goals, TPACK only refers to the specific nature of teacher's PCK (Phillips \& Harris, 2018).

From the keyword analysis, we can see that "digital competence", "educational technology", "learning by design" are hotpots of TPACK research. In addition, between 2009 and 2014, the research topic "Communication Technologies" was developed rapidly, and from 2014 to 2016, the research topic "Content Analysis" was also with the high-speed development. In recent years, some emerging research topics, such as "learning activity", "professional knowledge", "pedagogical model", "teaching materials" have also been well developed and have shown a certain vitality.

Looking forward to breakthroughs and innovations in TPACK research, it is necessary to strengthen research and excavation in educational theory, teacher education, educational technology, learning process in practice. From the overall development situation, TPACK research will pay more and more attention to practical research, be more closely related to teachers' teaching and students' learning, rather than just a kind of theoretical analysis, and be integrated with more fields in the future.

\section{Conclusion}

In this study, 844 published papers on TPACK were chosen as the research object in the WOS core collection database between 2009 to 2020. This study used CiteSpace software to analyze the authors, research institutions, cited articles and keywords of the literature visually. Finally, according to visual analysis results, research hotspots and trends of TPACK are concluded. TPACK is the most crucial research hotspot in the field of TPACK, including theoretical and practical research. To be more specific, "digital competence", "educational technology", "learning by design" are hotpots of TPACK research. By detecting burst terms, it shows some emerging research topics with vitality, such as "learning activity", "professional knowledge", "pedagogical model", "teaching materials", 
which are research fronts and development trends of this field in recent years.

However, there are still some limitations in the conclusions. Firstly, this study used Citespace software to analyze the literature, but there are many tools available for bibliometric visual analysis, and the results may not be the same by using different software. Secondly, due to the limited experience and ability of researchers, there may inevitably be some deviations in the prediction of development trends, hoping that future research can refine these shortcomings and limitations.

The current TPACK research still has great space for improvement and optimization. First of all, it's necessary to strengthen cooperation between scholars and research institutions of TPACK. Second, TPACK research should closely follow the development needs of the times and maximize TPACK research value; third, vigorously promote the integration of multiple disciplines to promote the study and development of this research field. Scholars should keep up with the trend and conduct further exploration on TPACK research.

\section{Funding}

This research was supported by the Priority Academic Program Development of Jiangsu Higher Education Institutions in China.

\section{Author Contributions}

Wei He designed the research at the beginning. Chuan Xue analyzed the data, and prepared the first draft of the paper. Wei He as the corresponding author contributed to the revision. All authors approved the final draft.

\section{Conflicts of Interest}

The authors declare no conflicts of interest regarding the publication of this paper.

\section{References}

Archambault, L., \& Crippen, K. (2009). Examining TPACK among K-12 Online Distance Educators in the United States. Contemporary Issues in Technology and Teacher Education, 9, 71-88. https://www.researchgate.net/publication/255629738

Bar-Ilan, J. (2007). Which h-Index? - A Comparison of WoS, Scopus and Google Scholar. Scientometrics, 74, 257-271. https://doi.org/10.1007/s11192-008-0216-y

Cabero, J., \& Barroso, J. (2016). ICT Teacher Training: A View of the TPACK Model/Formación del profesorado en TIC: Una visión del modelo TPACK. Culture and Education, 28, 633-663. https://doi.org/10.1080/11356405.2016.1203526

Chai, C. S., Koh J. H. L., Tsai, C. C., \& Tan, L. L. W. (2011). Modeling Primary School Pre-Service Teachers' Technological Pedagogical Content Knowledge (TPACK) for Meaningful Learning with Information and Communication Technology (ICT). Computers \& Education, 57, 1184-1193. https://doi.org/10.1016/j.compedu.2011.01.007

Chai, C. S., Koh, J. H. L., \& Tsai, C. C. (2016). A Review of the Quantitative Measures of Technological Pedagogical Content Knowledge (TPACK). In M. C. Herring, M. J. 
Koehler, \& P. Mishra (Eds.), Handbook of Technological Pedagogical Content Knowledge (TPACK) for Educators (2nd ed., pp. 87-106). New York: Routledge.

https://books.google.com.hk/books?id=v0d-CwAAQBAJ\&lpg=PA87\&ots=oZ38K4X8G t\&dq=6A\%20Review\%20of\%20the\%20Quantitative\%20Measures\%20of\%20Technologi cal\%20Pedagogical\%20Content $\% 20$ Knowledge $\% 20$ (TPACK) \&lr\&hl=zh-CN\&pg=PA87 $\# \mathrm{v}=$ onepage\&q\&f=false

Doering, A., Veletsianos, G., Scharber, C., \& Miller, C. (2009). Using the Technological, Pedagogical, and Content Knowledge Framework to Design Online Learning Environments and Professional Development. Journal of Educational Computing Research, 41, 319-346. https://doi.org/10.2190/EC.41.3.d

Falagas, M. E., Pitsouni, E. I., Malietzis, G. A., \& Pappas, G. (2008). Comparison of PubMed, Scopus, Web of Science, and Google Scholar: Strengths and Weaknesses. The FASEB Journal, 22, 338-342. https://doi.org/10.1096/fj.07-9492LSF

Franco, M., \& Pinho, C. (2019). A Case Study about Cooperation between University Research Centres: Knowledge Transfer Perspective. Journal of Innovation \& Knowledge, 4, 62-69. https://doi.org/10.1016/j.jik.2018.03.003

Gür, H., \& Karamete, A. (2015). A Short Review of TPACK for Teacher Education. Educational Research and Reviews, 10, 777-789. https://doi.org/10.5897/ERR2014.1982

Koehler, M. J., \& Mishra, P. (2005). What Happens When Teachers Design Educational Technology? The Development of Technological Pedagogical Content Knowledge. Journal of Educational Computing Research, 32, 131-152. https://doi.org/10.2190/0EW7-01WB-BKHL-QDYV

Koehler, M., \& Mishra, P. (2009). What Is Technological Pedagogical Content Knowledge (TPACK)? Contemporary Issues in Technology and Teacher Education, 9, 60-70. https://www.learntechlib.org/primary/p/29544

Koh, J. H. L., Chai, C. S., Benjamin, W., \& Hong, H. Y. (2015). Technological Pedagogical Content Knowledge (TPACK) and Design Thinking: A Framework to Support ICT Lesson Design for 21st Century Learning. The Asia-Pacific Education Researcher, 24, 535-543. https://doi.org/10.1007/s40299-015-0237-2

Lu, L., Johnson, L., Tolley, L., Gilliard-Cook, T., \& Lei, J. (2011). Learning by Design: TPACK in Action. In M. Koehler, \& P. Mishra (Eds.), Proceedings of SITE 2011-Society for Information Technology \& Teacher Education International Conference (pp. 4388-4395). Nashville, TE: Association for the Advancement of Computing in Education (AACE). https://www.learntechlib.org/primary/p/37022

Olofson, M. W., Swallow, M. J., \& Neumann, M. D. (2016). TPACKing: A Constructivist Framing of TPACK to Analyze Teachers' Construction of Knowledge. Computers \& Education, 95, 188-201. https://doi.org/10.1016/j.compedu.2015.12.010

Phillips, M., \& Harris, J. (2018). PCK and TPCK/TPACK: More than Etiology. In E. Langran, \& J. Borup (Eds.), Proceedings of Society for Information Technology \& Teacher Education International Conference (pp. 2109-2116). Washington DC: Association for the Advancement of Computing in Education (AACE).

https://www.learntechlib.org/primary/p/182817

Price, D. J. D. S. (1963). Little Science, Big Science. New York: Columbia University Press. https://doi.org/10.7312/pric91844

Redecker, C., \& Punie, Y. (2017). European Framework for the Digital Competence of Educators: DigCompEdu. Luxembourg: Publications Office of the European Union.

Shulman, L. S. (1986). Those Who Understand: Knowledge Growth in Teaching. Educational Researcher, 15, 4-14. https://doi.org/10.3102/0013189X015002004

Small, H. (1973). Co-Citation in the Scientific Literature: A New Measure of the Rela- 
tionship between Two Documents. Journal of the American Society for Information Science, 24, 265-269. https://doi.org/10.1002/asi.4630240406

Synnestvedt, M. B., Chen, C., \& Holmes, J. H. (2005). CiteSpace II: Visualization and Knowledge Discovery in Bibliographic Databases. AMIA Annual Symposium Proceedings, 2005, 724-728. https://www.ncbi.nlm.nih.gov/pmc/articles/PMC1560567

Voogt, J., Fisser, P., Pareja Roblin, N., Tondeur, J., \& van Braak, J. (2013). Technological Pedagogical Content Knowledge a Review of the Literature. Journal of Computer Assisted Learning, 29, 109-121. https://doi.org/10.1111/j.1365-2729.2012.00487.x

Wang, W., Schmidt-Crawford, D., \& Jin, Y. (2018). Preservice Teachers' TPACK Development: A Review of Literature. Journal of Digital Learning in Teacher Education, 34, 234-258. https://doi.org/10.1080/21532974.2018.1498039 